\title{
A abolição sob a lente de autores brasileiros
}

\author{
The abolition under the lens of Brazilian authors \\ José ANTÓNIO CARVALho Dias DE ABREU \\ Universidade de Coimbra - Coimbra - Portugal
}

a

\begin{abstract}
Resumo: No século da independência, do Império e da República, a existência do sistema esclavagista marcou decisivamente a história do Brasil, condicionando as mentalidades e o futuro da nação. Como tal, perante uma realidade insofismável, este trabalho procura demonstrar como no "século negro" a escravidão, a abolição, as relações entre senhores e escravos se estabeleceram, trazendo para a cena literária romances, contos, crónicas, de referências da literatura do Brasil, quase todas de autores bem conhecidos: Maria Firmina dos Reis, Joaquim Manuel de Macedo, Bernardo Guimarães, Aluísio Azevedo, e, não menos importante, Machado de Assis. Sob o manto da segurança do fazendeiro, do preconceito da cor, da sentimentalidade, da crítica ao desejo de notoriedade burguesa, da denúncia da violência escravocrata, estes escritores, uns de forma mais consciente e crítica do que outros, evidenciando uma leitura histórica, social e política que problematiza as estruturas de domínio da sociedade brasileira e a forma como exercem a sua autoridade, escreveram e conceberam, indubitavelmente, a história brasileira de oitocentos.
\end{abstract}

Palavras-chave: Literatura; Escravatura; Abolicionismo

\begin{abstract}
In the century of Independence, of the Empire and the Republic, the existence of the slavery system decisively marked the history of Brazil, conditioning mentalities and the future of this nation. Thus, before an undisputable reality, this paper attempts to demonstrate how slavery, abolition and relationships between masters and slaves were established in the "black century", bringing into the literary scene novels, short stories, chronicles, which are references of the Brazilian literature, nearly all written by well-known authors: Maria Firmina dos Reis, Joaquim Manuel de Macedo, Bernardo Guimarães, Aluísio Azevedo, and last but not least, Machado de Assis. Under the lord's safety cloak, under the prejudice of colour, under sentimentality and the criticism of the bourgeois desire for notoriety, under the denunciation of the slavery violence, these writers, some in a more conscious, critical way than others, showing an historical, social and political reading, which questions the dominant structures of the Brazilian society and the way they apply their authority, undoubtedly wrote and conceived the Brazilian history of the 19.th century.
\end{abstract}

Keywords: Literature; Slavery; Abolitionism

\section{A literatura no Brasil Império: que recorte?}

Abarcando um largo período temporal, da década de 50 à primeira década do século XX, esta análise do tratamento da escravidão, do abolicionismo e das relações de poder entre senhores e cativos, incide em romances de Maria Firmina dos Reis ${ }^{1}$, Joaquim Manuel de Macedo $^{2}$, Bernardo Guimarães ${ }^{3}$, Aluísio Azevedo ${ }^{4}$ e Machado de Assis $^{5}$, assim como também em alguns contos $^{6}$ e crónicas deste último, que demonstram, sem margem para dúvidas, as diversas formas como foi olhado o problema da escravatura e defenderam, em- bora uns mais explicitamente do que outros, a sua abolição.

Num primeiro momento, deve-se dizer que quer Joaquim Manuel de Macedo quer Bernardo Guimarães,

1 Úrsula (1859).

2 As Vitimas Algozes (1869).

3 A Escrava Isaura (1875).

4 O Mulato (1881) e O Cortiço (1890).

5 Helena (1876), Iaiá Garcia (1878), Memórias Póstumas de Brás Cubas (1881), Quincas Borba (1891), Dom Casmurro (1899), Memorial de Aires (1908).

6 "Virginius" (1864), "Mariana" (1871), "O Espelho" (1882), “O Caso da Vara" (1891), "Pai Contra Mãe" (1906). 
sobretudo o primeiro, não se limitando a escrever para entreter um público essencialmente feminino e burguês, numa época romântica que pretendia encontrar as suas raízes e a sua identidade, procuraram com os seus textos modelar a sociedade, configurar mentalidades, provando que entre a história e a literatura a ligação é sempre próxima e cúmplice.

Nessa espécie de missão histórica que a literatura empreende, estes dois escritores veiculam uma determinada mentalidade, que se consubstancia naquilo que se pode designar como quadros-padrão que plasmam uma mundividência patriarcal.

$\mathrm{Na}$ verdade, tanto As Vitimas-Algozes como A Escrava Isaura, apesar de serem consideradas por muitos autores obras abolicionistas, não fizeram mais do que ajudar a configurar uma mentalidade patriarcal que via uma sociedade assente nas virtudes e nos princípios morais de um senhor, branco, e detentor de qualidades extraordinárias.

É nessa medida que a generosidade, a sua capacidade de trabalho, o culto da família, o amor maternal, a filantropia, o branco como belo e o negro como feio, constituem alguns dos aspetos que ajudam a caracterizar o branco.

Só a heroicidade maternal, que excede a todas as heroicidades, podia explicar a paciência, a constância e a força angélica que animavam a vítima. Teresa não vivia mais para si, nem para as ilusões do mundo: por assim dizer suicidara-se, caindo na sepultura do gabinete escolhido: era somente o amor maternal, o seu amor d'alma túmulo que prendia sua sombra àquele retiro para velar incessante pelos filhos, que aliás nunca lhe foram disputados. (AVA, 1991, p. 121)

Todavia, como para indenizá-la [a Isaura] de tamanha desventura, uma santa mulher, um anjo de bondade, curvou-se sobre o berço da pobre criança e veio ampará-la à sombra de suas asas caridosas. A mulher do comendador considerou aquela tenra e formosa cria como um mimo, que o céu lhe enviava para consolá-la das angústias e dissabores, que tragava em consequência dos torpes desmandos de seu devasso marido.

Levantou ao céu os olhos banhados em lágrimas, e jurou pela alma da infeliz mulata encarregar-se do futuro de Isaura, criá-la e educá-la, como se fosse uma filha.

Assim o cumpriu com o mais religioso escrúpulo. À medida que a menina foi crescendo e entrando em idade de aprender, foi-lhe ela mesma ensinando a ler e escrever, a coser e a rezar. Mais tarde procurou-lhe também mestres de música, de dança, de italiano, de francês, de desenho, comprou-lhe livros, e empenhou-se enfim em dar à menina a mais esmerada e fina educação, como o faria para com uma filha querida. (AEI, 1981, p. 17)
E se, a estes aspetos, juntarmos a caracterização feita dos escravos, a apologia da submissão e da humildade dos cativos ao senhor, a intenção de reproduzir e perpetuar um quadro patriarcal fica completa:

- Podes dizer o que quiseres, Rosa; mas eu bem sei, que na sala ou na cozinha eu não sou mais do que uma escrava como tu. Também deves-te lembrar, que se hoje te achas aqui, amanhã sabe Deus, onde estarás. Trabalhemos, que é nossa obrigação, deixemos dessas conversas que não têm graça nenhuma. (AEI, 1981, p. 42)

\section{A abolição como estratégia dissimulatória}

Estes autores, como estratégia para defender o regime instituído, construíram aquilo que se pode designar como fórmula para o domínio branco que passou: pela defesa da cor negra como sinónimo de inferioridade o que evidencia os preconceitos rácicos; e pela construção de estereótipos.

Em As Vitimas Algozes, constata-se uma padronização assente na negatividade e na inferioridade. Com isto, pretende-se a eternização da condição subserviente e esvazia-se o escravo de características individualizantes. Macedo parte da ideia de que o escravo é uma ameaça, e, por isso, o retrato é o pior possível. Os escravos são vistos num único sentido, dominados pela desumanização e animalidade (Simeão: quando aprecia os seios de Florinda; quando ruge após saber do casamento de Florinda; quando, após a leitura do testamento, é associado a um tigre. Esméria quando açoita as colegas. Pai Raiol: quando é associado à serpente símbolo do veneno e da perfídia; quando se expressa em monossílabos; quando luta animalescamente com Tio Alberto); pela insensibilidade, sensualismo e devassidão (Simeão não sofre com a morte de Domingos Caetano; a relação amorosa dos negros, lasciva, carnal, instintiva, sem sentimentos profundos); pela dissimulação, traição, malícia e perversão (Esméria quando se mostra humilde, simples, submissa, obediente, cuidadosa com os filhos de Teresa; Lucinda quando aconselha Cândida a ter cuidado com os pretendentes; quando sugere que Cândida aborte, sabendo que ela recusará; quando atraiçoa Cândida).

No seu conjunto, estas características conduzem a um processo progressivo e paradigmático de diabolização do escravo e a mensagem é, por isso, simbolicamente terrível: se não se acaba com a escravidão, a família brasileira está condenada (no final de "Simeão, o Crioulo", depois de se denunciarem os crimes do protagonista e de se afirmar que "a escravidão degrada, deprava, e torna o homem capaz dos mais medonhos crimes", o fim do sistema escravocrata é apontado como a única solução para acabar como os inúmeros Simeões que, generalizadamente, contaminam com o seu veneno a sociedade brasileira: "Se 
quereis matar Simeão, acabar com Simeão, matai a mãe do crime, acabai com a escravidão." (AVA, 1991, p. 68).

Em Bernardo Guimarães, o escravo aparece mais humanizado, detentor de sentimentos e sem diabolização, no entanto Isaura não constitui uma inversão do estereótipo do escravo, já que é apresentada como branca. A cor e a excecionalidade condicionam essa leitura.

A humanidade e as virtudes da personagem, apresentada como uma mulher-anjo resignada e submissa, não são suficientes para considerar a obra como defensora dos cativos, pois Bernardo Guimarães não estende essas características aos outros escravos. Exemplo disso é Rosa, a encarnação da escrava invejosa, sedutora, malévola:

- Sinhá está-se fiando muito naquela sonsa dizia-lhe a maliciosa rapariga. - Pois fique certa, que não são de hoje esses namoricos; há muito tempo, que eu estou vendo essa impostora, que diante da sinhá se faz toda simplória, andar-se derretendo diante de sinhô moço. Ela mesmo é que tem a culpa de ele andar assim com a cabeça virada. (AEI, 1981, p. 49)

Perante este quadro, é fundamental questionar se, afinal, As Vitimas Algozes e A Escrava Isaura defendem ou não a abolição da escravatura. Efetivamente, estes textos defendem a abolição, porém, a desculpabilização e a vitimização dos senhores que se junta ao medo que estes sentem dos escravos, à metaforização da escravatura no amor, ao facto de a escravidão ser um acidente provocado pelo destino, à apologia da submissão, se não põem em causa, esmaecem a intenção abolicionista.

Pode-se mesmo afirmar que, mais do que o sofrimento escravo, são as consequências negativas para os senhores que levam Macedo e Guimarães a apelar à abolição. A preocupação desses escritores não é retratar a situação miserável, as humilhações, as punições, a ausência de educação dada aos escravos. O que os preocupa é a defesa dos senhores, de um poder instituído. A defesa da abolição, afinal, não passa nestes romances de uma estratégia dissimulatória, como se pode ver nas palavras abaixo, que justificam seu término pelos males que traz aos senhores:

- Oh! Bani a escravidão!... A escravidão é um crime da sociedade escravagista, e a escravidão se vinga desmoralizando, envenenando, desonrando, empestando, assassinando seus opressores. Oh!... Bani a escravidão! Bani a escravidão! Bani a escravidão!... $(A V A, 1991$, p. 314)

\section{Maria Firmina dos Reis, a voz contracorrente}

Se o escravo apresentado nos textos de Macedo e de Guimarães pode ser considerado o padrão na narrativa brasileira de pendor abolicionista, o romance de Maria Firmina dos Reis, apresenta um escravo divergente. $\mathrm{Na}$ realidade, publicado em 1859, Úrsula assume um papel fraturante na literatura brasileira. Este texto denuncia efetivamente o rigor do cativeiro. Assumindo a sua afro-brasilidade, Firmina dos Reis tem a coragem de se mostrar solidária com a dor do escravo negro e apresentálo generalizadamente como digno, humano e sensível, ao mesmo tempo que, invertendo estereótipos, mostra um senhor frio, desumano, cuja encarnação é Fernando.

Susana, Túlio sobretudo, mas também Antero e todos os outros escravos, são retratados como seres generosos, plenos de humanidade, com sentido de honra e de dignidade, e, não menos importante, com capacidade para recordar os seus costumes, o seu passado, a sua história.

Charles Martin, no prefácio à $3^{\mathfrak{a}}$ edição do romance, enfatiza, desde logo, que se reconhece uma "genuína preocupação com a história, o elo com a África e a consciência com as próprias raízes" (MARTIN, 1988, p. 10), facto que não se verificava nos textos que, antes e depois do de Maria Firmina dos Reis, representavam os negros. Esse vínculo, juntamente com a caracterização do negro, fazem o crítico afirmar que o livro tem como intuito apresentar "uma nova visão do passado africano" (MARTIN, 1988, p. 10).

No mesmo sentido, Eduardo Assis Duarte considera Úrsula "o primeiro romance da literatura afro-brasileira que tematiza o assunto do negro a partir de uma perspectiva interna e comprometida politicamente em recuperar e narrar a condição do ser negro em nosso país." (DUARTE, 2004, p. 280).

Apresentando o escravo como sujeito, o texto de Firmina não se restringe à mera denúncia pontual, que no decorrer da narrativa é sistemática e demolidora. Úrsula, ideologicamente, ultrapassa as concessões paternalistas e beneméritas de Guimarães que só é capaz de apresentar um escravo protagonista generoso e digno, como branco. O romance de 1859 sobrepuja, antes do tempo, o conceito que Macedo e Guimarães formulam do escravo. A escritora maranhense - para quem o escravo não é o repositório de todos os vícios -, com a intenção de exigir para o cativo a liberdade, esboça um novo escravo-padrão: bondoso, respeitador do sofrimento alheio, solidário e capaz de salvar o branco.

Inovadoramente, Firmina dos Reis, além de assumir não apenas a diferença, a rutura com uma tradição literária baseada no paternalismo e no racismo, onde o cativo, desprovido de humanidade, inexistia como sujeito, concede ao negro aquilo que lhe estava vedado na narrativa brasileira, a voz. Zahidé Muzart julga mesmo que, além de se tentar desconstruir uma história literária baseada numa perspetiva etnocêntrica e masculinizante, em Úrsula se assiste pela primeira vez ao facto de 
os escravos terem direito a uma voz, que lhes permite rememorar o continente africano como terra de liberdade (cf. MUZART, 2000, p. 266). Susana e Túlio são as vozes alternativas de uma história brasileira feita por brancos que vê o negro como um ser inferior, "despossuído". Em Úrsula, o escravo, afinal, não é o algoz, indigente, desumano, selvagem. Ao contrário, ele é vítima, empreendedor, sensível, um ser humano que preza a família. O escravo, afinal, não é inferior, mas colocado num patamar de referência comparativa.

Como uma escrita da memória que une passado e presente, Úrsula, ao dar voz ao outro despojado da sua terra e da sua família, aparece na literatura brasileira como a tentativa de questionar o sistema esclavagista e denunciá-lo nos seus horrores, ao mesmo tempo que relembra, sob o testemunho de Susana, o que realmente aconteceu na diáspora dos africanos, evitando que o sofrimento do escravo seja apagado ou mitigado. Nesta medida, este é um texto inaugural que tenta escrever uma outra história para o Brasil, dando ao escravo um papel de sujeito:

- [...] Foi embalde que supliquei em nome de minha filha, que me restituíssem a liberdade: os bárbaros sorriam-se de minhas lágrimas, e olhavam-me sem compaixão. [...] Meteram-me a mim e a mais trezentos companheiros de infortúnio e de cativeiro no estreito e infecto porão de um navio. Trinta dias de cruéis tormentos, e de falta absoluta de tudo quanto é necessário à vida passamos nessa sepultura até que abordamos as praias brasileiras. Para caber a mercadoria humana no porão fomos amarrados em pé para que não houvesse receio de revolta, acorrentados como animais ferozes das nossas matas que se levam para recreio dos potentados da Europa. (U, 2004, p. 117$)^{7}$

\section{Aluísio e Machado: que escravidão e abolição?}

Mesmo sem a abolição como tema central, os romances $O$ Mulato e $O$ Cortiço, de Aluísio Azevedo, têm subjacentes quer a escravidão quer a exigência da emancipação escrava.

Na verdade, n' O Mulato, com um homem de cor como protagonista - ainda que esmaecido na sua tonalidade e com uma cultura ocidental -, o que se constata ao longo da ação é um sentimento preconceituoso exacerbado na sociedade maranhense.

O quadro caricatural traçado de São Luís traz à evidência um comportamento que se pauta pela noção da superioridade dos brancos sobre os negros e os mulatos.

\footnotetext{
Esta passagem mostra uma denúncia feita de forma mais direta do que a de Castro Alves no "Navio Negreiro", porque posto na boca da própria personagem e não na de um sujeito poético, como no poeta baiano.
}

A imagem desenhada do branco é muito negativa: ele tanto é capaz dos atos mais violentos e autocráticos perante os escravos (Quitéria e Maria Bárbara são o rosto mais visível dum exercício de poder rigoroso e insensível exercido sobre Domingas ou Benedito), como de atos mais simbólicos que exprimem uma mentalidade preconceituosa quanto à cor (a oposição de toda a família de Ana Rosa ao casamento com o primo é exemplo paradigmático).

Porém, esta obra que aparentemente se erige como crítica severa contra tal conservadorismo acaba por revelar ambiguamente o próprio preconceito do escritor-narrador e do protagonista. A imagem negativa com que alguns escravos são apresentados, a que se junta um desenho de Raimundo que amaldiçoa as suas origens, demonstram que também Aluísio - à semelhança de outros intelectuais na época - encara o africano como inferior e não o vê como um elemento construtor do Brasil.

O comportamento de Raimundo ao longo da ação é revelador do que se acaba de dizer. Sem que nada o fizesse prever é o próprio mulato - com uma formação europeia, positivista e crítico da mesquinhez maranhense - que permite a afirmação de que não é possível fugir a ideias pré-concebidas.

Com um comportamento oscilante, o protagonista configura o retrato do ser individual que se sobrepõe ao ser social, do ser romântico que se sobrepõe ao ser naturalista, esbatendo naturalmente uma crítica mais incisiva ao sistema esclavagista e à mentalidade que o sustentava.

Essa assunção do ser individual verifica-se de duas formas: por um lado, no orgulho ferido e na vaidade, por ver a sua posição social ser questionada; e, por outro lado, no sentimento amoroso por Ana Rosa ser colocado em causa pelas suas origens africanas. Quer uma quer outra explicam, não apenas o fatalismo da aceitação da sua ascendência, mas também as posições mais assertivas e emotivas, pontuais, nunca sistemáticas, contra a escravidão e quase nunca contra o preconceito da cor, porque ele próprio também o manifesta:

- Para que não te arrependas de me haver escolhido por esposo e não me crimines a mim por me ter portado silencioso e covarde defronte da recusa de teu pai, sabe minha querida amiga, que o pior momento da minha pobre vida foi aquele em que vi inevitável fugir-te para sempre. Mas que fazer? - eu nasci escravo e sou filho de uma negra. Empenhei a teu pai minha palavra em como nunca procuraria casar contigo; bem pouco porém me importava o compromisso! que não teria eu sacrificado pelo teu amor?

- Ah! mas é que essa mesma dedicação seria a tua desgraça e transformaria o meu ídolo em minha vítima; a sociedade apontar-te-ia como a mulher de um mulato e nossos descendentes teriam casta e seriam tão desgraçados quanto eu! Entendi, pois, que fugindo, te daria a maior prova do meu amor. (OM, 1970, p. 241) 
O Cortiço apresenta um viés diferente na forma de encarar a escravidão e a abolição. Aparentemente diluídas na dimensão naturalista do texto e nas relações diversas que se estabelecem entre as personagens, essas temáticas estão presentes no romance do início ao fim, sobretudo através de Bertoleza.

Com a ação a decorrer depois da Lei do Ventre Livre, Bertoleza, duplamente explorada pelo seu senhor e por João Romão, é a síntese do escravo que permite o sustento e a ascensão do branco.

A relação entre João Romão e a negra é a todos os títulos exemplar como que representando alegoricamente o Brasil e a ascensão da burguesia. Aluísio não deixa muitas dúvidas na sua crítica ao oportunismo burguês. Promovendo uma política de dependência e de favor, o senhor consegue não apenas a gratidão eterna do escravo ou liberto e a sua riqueza, mas também uma posição futura de relevo na sociedade.

Com um alcance significativo, a configuração de Bertoleza ajuda a dar um sentido novo à história brasileira. Com ela, revela-se não apenas o oportunismo duma classe capitalista emergente, mas também, na parte final do romance, a forma subversiva como reage.

Bertoleza não se resigna e, numa atitude pouco comum no desenho das personagens negras da literatura brasileira do século XIX, recusa ser tratada como um animal. Ela reclama, com a sua voz, a sua dignidade e, não menos importante, exige de Romão a sua gratidão, o que inverte o padrão do relacionamento entre senhor e negro naquele momento da história brasileira em que ainda existia a escravatura.

Ao não querer ser tratada como um objeto, é a sua individualidade que está em causa, o seu ser enquanto mulher, plena de direitos, numa tentativa de paridade com o branco que, efetivamente, ainda não é possível no Brasil da década de 70 nem no pós-abolição:

- Ah! agora não me enxergo! agora eu não presto para nada! Porém, quando você precisou de mim não lhe ficava mal servir-se de meu corpo e aguentar a sua casa com o meu trabalho! Então a negra servia pra um tudo; agora não presta pra mais nada, e atira-se com ela no monturo do cisco! Não! assim também Deus não manda! Pois se aos cães velhos não se enxotam, por que me hão de pôr fora desta casa, em que meti muito suor do meu rosto?... Quer casar, espere então que eu feche primeiro os olhos; não seja ingrato! ( $O C$, 1962, p. 241)

Após perceber que não passa de um objeto e que João Romão se quer ver livre dela, reivindica o seu quinhão junto do novel capitalista e depois, compreendendo que era ainda escrava, Bertoleza, num desenho humanizado, põe termo à vida.
O seu suicídio, mais do que um ato desesperado, representa simbolicamente o resgate efetivo e radical da sua liberdade, evitando o regresso ao cativeiro. Bertoleza suicida-se para não ser escrava novamente, erigindo-se a morte (como no conto de Machado de Assis, "Virginius", em que Julião mata a filha para defender a sua honra) como o caminho para atingir a emancipação e fugir à desonra, à humilhação.

Ao mesmo tempo, Aluísio constrói um cenário em que os mais poderosos apenas veem o mundo em função dos seus anseios. Para eles, de quem João Romão e Miranda são exemplos, não existe a noção de alteridade. Inescrupulosos e imorais, os mais poderosos encaram os outros apenas como objetos que se usam e se descartam quando desnecessários:

- Mas não vês que isso é um disparate?... Tu não te conheces?... Eu te estimo, filha; mas por ti farei o que for bem entendido e não loucuras! Descansa que nada te há de faltar!... Tinha graça, com efeito, que ficássemos vivendo juntos! Não sei como não me propões casamento! (OC, 1962, p. 240-241)

Percebe-se por isso que, para manter a ordem social de domínio, se convoque a escravidão não já como sistema de produção, mas como forma de controlo. Vendo a situação descontrolada com as reivindicações de Bertoleza e a sua autoridade colocada em causa, Romão lembra-se que ela era ainda uma escrava.

Provando que o abolicionismo é um tema presente e que a sociedade brasileira vive de aparências, a fechar o romance evidencia-se ironicamente o convite para João Romão integrar um comité abolicionista.

Com alcance histórico claro, tal facto reveste-se de grande relevância, na medida em que permite perceber o pensamento do escritor acerca do futuro do escravo/ liberto no Brasil: juridicamente livre, mas efetivamente dependente.

Se todos os romances apontados anteriormente se ligam de alguma forma explícita à escravidão, ao abolicionismo, a obra machadiana constituiu um desafio, até porque alguma crítica continua a ver Machado de Assis como um escritor que não se interessou pelos problemas do seu tempo.

Perscrutando toda a sua longa produção literária, à exceção da poesia e dos textos dramáticos, percebeuse que, de forma muito sui generis, com uma escrita irónica, o escritor apresenta uma visão crítica sobre a sua época e em particular sobre a escravidão e o abolicionismo.

Se aparentemente muitos dos seus textos nem sequer apresentam um negro ou um escravo na intriga ou quando este aparece, desempenhando um papel secundário, raramente tem voz, outros há em que a sua presença 
permite desvelar o pensamento mais recôndito do autor e ajudar a escrever a história do Brasil.

$\mathrm{Na}$ realidade, quase sempre de forma alegórica e quase nunca através da palavra do negro, do homem de cor, do escravo - mas sob a voz de outras personagens -, Machado expõe as relações sociais de poder que se estabeleciam entre senhores e escravos nos dois últimos quartéis de oitocentos.

Não se pense contudo que essa presença do escravo e o pensamento sobre a abolição é clara. Pelo contrário. A escravidão e a abolição não são percetíveis pelo número de personagens escravas existente nas obras de Machado ou pelos comentários explícitos que as personagens possam fazer, criticando a existência da escravatura ou defendendo a sua abolição. Essas temáticas devem ser sempre vistas na perspetiva em que há um senhor proprietário e escravos que mantêm entre si laços baseados na dependência e na autoridade ${ }^{8}$.

Na verdade, com uma escrita dissimulada, o autor de Dom Casmurro constrói nas suas narrativas uma imagem do Brasil onde é percetível uma relação desigual entre uma classe dirigente senhorial e o homem de cor, escravo ou liberto.

Assim, as referências à escravidão, mais aludida do que explícita, surgem sem dúvida com uma intenção condenatória do regime esclavagista.

Por isso, aparecem senhores protagonistas como Estácio, Brás Cubas, Bento, Barão de Santa Pia, Coutinho, Jacobina, Cristiano Palha, que não admitem a alteridade e veem o mundo apenas em virtude dos seus desejos e interesses. Para eles, o outro não existe. Como bem assinalou Sidney Chalhoub, analisando o romance Helena, "na visão do mundo de Estácio não haveria lugar para a noção de reciprocidade, não existiria espaço para o reconhecimento dos direitos de outrem" (Chalhoub, 2003, p. 28).

Em sentido contrário, Vicente, Raimundo, Prudêncio, Julião e Elisa, Mariana, Lucrécia, Arminda, Clarimunda, Pancrácio, Silvério, comprovam a atenção do escritor ao papel que o escravo ocupa na sociedade, seja a ajudar a jovem senhora, seja a defender a sua honra, seja a proteger a maternidade, seja ainda a ser vítima de violência ou a suicidar-se.

Por outro lado, a narrativa machadiana, mesmo não lhe conferindo voz ou qualquer protagonismo, constrói uma imagem do escravo que não é negativa e muito menos maléfica. Ao contrário, o sentimento expresso por diferentes narradores machadianos é de empatia e até de

\footnotetext{
8 Para Sidney Chalhoub, que investigou a vida de Machado como funcionário público, em particular no Ministério da Agricultura, os textos do escritor expressam alegórica, mas inequivocamente, as relações sociais de dominação exercidas pelo poder instituído sobre os escravos e aqueles que denomina por dependentes (cf. CHALHOUB, 2003, p. 9).
}

solidariedade com o sofrimento manifestado pelos cativos. Não é por acaso que, sobretudo nos contos, a violência, seja ela física, sexual ou simplesmente simbólica, aparece recorrentemente em "Virginius", "Mariana", em "O Caso da Vara", ou em "Pai Contra Mãe":

- Sr. Damião, dê-me aquela vara, faz favor?

Damião ficou frio... Cruel instante! Uma nuvem passou-lhe pelos olhos. Sim, tinha jurado apadrinhar a pequena, que por causa dele, atrasara o trabalho...

- Dê-me a vara, Sr. Damião! [...]

- Me acuda, meu sinhô moço!

Sinhá Rita, com a cara em fogo e os olhos esbugalhados, instava pela vara, sem largar a negrinha, agora presa de um acesso de tosse. Damião sentiu-se compungido; mas ele precisava tanto sair do seminário! Chegou à marquesa, pegou na vara e entregou-a a Sinhá Rita. (OCV, 2004b, 582)

- Aqui está a fujona, disse Cândido Neves. - É ela mesma. - Meu senhor!

- Anda, entra...

Arminda caiu no corredor. Ali mesmo o senhor da escrava abriu a carteira e tirou os cem mil-réis de gratificação. Cândido Neves guardou as duas notas de cinquenta mil-réis, enquanto o senhor novamente dizia à escrava que entrasse.[...]

No chão, onde jazia, levada do medo e da dor, e após algum tempo de luta a escrava abortou.

$\mathrm{O}$ fruto de algum tempo entrou sem vida neste mundo, entre os gemidos da mãe e os gestos de desespero do dono. (PCM, 2004b, p. 667)

Porém, essa espécie de solidariedade manifestada com o cativo não parece ser suficiente para afirmar que Machado adota um comportamento afro-brasileiro, ao contrário do que afirma Eduardo Assis Duarte. Para este investigador, não negando que há uma dimensão universal na produção literária de Machado que o alcandora ao estatuto de grande escritor da humanidade, entende que a visão da sociedade brasileira transmitida nos seus textos é a de um afro-brasileiro, que o afasta de uma conceção negativa do negro, veiculada no romance de pendor abolicionista do século XIX:

Resta-nos, pois, adensar a reflexão rumo a essa outra faceta presente em Machado, a do escritor cuja perspectiva, emoldurada embora por toda uma poética da dissimulação, pertence ao sujeito afro-brasileiro que nele existe, apesar de todos os recalques. Isto porque provém de uma visão de mundo não-branca e, sobretudo, não-racista. É a partir dela que o romance machadiano se distancia tanto do projeto de fundação do ser nacional, presente no romantismo brasileiro, quanto do abolicionismo benevolente, preconceituoso e arianista, de Alencar, Macedo ou Bernardo Guimarães. (DUARTE, 2010, p. 6) 
Porém, mesmo focando os problemas sofridos, não parece que a preocupação de Machado se restrinja aos escravos. A sua preocupação parece ser a condição humana e a forma como os mais poderosos praticam o exercício de autoridade sobre os mais desfavorecidos, os mais dependentes, configurando relações sociais muito desiguais.

A forma como Machado vê o futuro do Brasil é sintomática duma visão pessimista. Por um lado, não crê que o escravo depois de libertado tenha as condições necessárias para se sustentar. Por outro lado, desnuda a intenção das classes mais poderosas, sob o manto da falsa filantropia, continuarem não apenas a granjear o favor e a dependência dos libertos, mas também a explorá-los com salários miseráveis. Para Machado, como afirma categoricamente John Gledson, a abolição da escravatura não "é um movimento da escuridão para a luz, mas a simples passagem de um relacionamento econômico e social opressivo para outro." (Gledson, 2003, p. 145).

$\mathrm{Na}$ verdade, apresentando uma sociedade desequilibrada em termos de poder, onde o branco exerce uma autoridade impiedosa e não questionável, e comete atropelos às leis emancipadoras, Machado não faz mais do que problematizar uma forma de organização social, um modo de produção que oprime os negros e os priva de liberdade.

Machado de Assis é também um abolicionista. Não um abolicionista como Macedo, preocupado com a segurança dos proprietários de escravos. Não um abolicionista como Guimarães, que ameniza o sofrimento escravo. Não um abolicionista como Aluísio, que insiste no preconceito da cor e na exploração do cativo. Nem tão pouco um abolicionista fraturante, como Maria Firmina. Mas de um abolicionismo outro, incisivo e satírico.

$\mathrm{Na}$ realidade, não obstante todos os escritores analisados abordarem a questão da abolição, os motivos por que o fazem e a visão tida do problema não é uniforme. Daí que se deva falar na literatura brasileira de Maria Firmina dos Reis a Machado de Assis em abolicionismos e não apenas em abolicionismo.

\section{Referências}

ASSIS, Machado de. "Crónicas" (1864-1867). In: Obras completas de Machado de Assis, v. 2. São Paulo: W. M. Jackson Editores, 1957.

ASSIS, Machado de, "Crónicas" (1878-1888). In: Obras completas de Machado de Assis, v. 4. São Paulo: W. M. Jackson Editores, 1957.

ASSIS, Machado de. Machado de Assis. Obra completa, v. 1 (Romance). Rio de Janeiro: Nova Aguilar, 2004a.

ASSIS, Machado de. Machado de Assis. Obra completa, v. 2 (Conto e Teatro). Rio de Janeiro: Nova Aguilar, 2004b.

ASSIS, Machado de. Machado de Assis. Obra completa, v. 3 (Poesia, Crónicas, Crítica). Rio de Janeiro: Nova Aguilar, 2004c.

AZEVEDO, Aluísio. O Cortiço. São Paulo: Livraria Martins Editora, 1962.

AZEVEDO, Aluísio. O Mulato. São Paulo: Livraria Martins Editora, 1970.

DUARTE, Eduardo Assis. Maria Firmina dos Reis e os Primórdios da Ficção Afro-brasileira. In: REIS, Maria Firmina, Úrsula. Minas Gerais: Editora Mulheres, 2004.

DUARTE, Eduardo Assis. Memórias Póstumas da Escravidão. In: BERNARDO, Gustavo, MICHAEL, Joachim, SCHÄFFAUER, Markus (Org.). Machado de Assis e a escravidão. São Paulo: Annablume, 2010.

GLEDSON, John. Machado de Assis: ficção e história. Rio de Janeiro: Paz e Terra, 2003.

GUIMARÃES, Bernardo. A escrava Isaura. São Paulo: Ática, 1981.

MACEDO, Joaquim Manuel de. As vítimas algozes: quadros da escravidão. São Paulo: Scipione, 1991.

MARTIN, Charles. Uma rara visão de liberdade. In: REIS, Maria Firmina. Úrsula. Rio de Janeiro: Presença, 1988.

MUZART, Zahidé. Lupinacci. Escritoras brasileiras do século XX. Florianópolis: Editora Mulheres, 2000.

REIS, Maria Firmina. Úrsula. Belo Horizonte: Editora Mulheres, 2004. 